\title{
Avaliação do crescimento de Gypsophila paniculata durante o enraizamento in vitro ${ }^{1}$
}

\author{
Nair Bosa ${ }^{2}$; Eunice Oliveira Calvete ${ }^{3}$; Marilei $\operatorname{Suzin}^{3}$; Lucrécia Bordignon ${ }^{3}$ \\ 2/EAFS, C. Postal 21, 99170-000 Sertão-RS; ${ }^{3 / F A M V-U P F, ~ C . ~ P o s t a l ~ 611, ~ 99001-070 ~ P a s s o ~ F u n d o-R S ; ~ E-m a i l: ~ c a l v e t e u @ u p f . t c h e . b r ~}$
}

\begin{abstract}
RESUMO
Gypsophila paniculata é uma flor de corte que pertence à família Caryophyllaceae. Conhecida popularmente por "mosquitinho", é comercializada para a confecção de arranjos e buquês. A propagação sexuada dessa espécie resulta em plantas desuniformes por ser geneticamente segregante. Por outro lado, a propagação vegetativa possibilita a disseminação de doenças, quando utiliza-se plantas infectadas. Assim, mediante a técnica de micropropagação, obtêmse mudas em escala comercial, com manutenção da heterose e livre de patógenos. Com o objetivo de analisar o crescimento de plantas de Gypsophila paniculata durante o enraizamento in vitro em diferentes períodos de cultivo, avaliou-se a matéria fresca e seca da parte aérea e da raiz aos $4 ; 8 ; 12 ; 16 ; 20$ e 24 dias. O delineamento experimental foi de blocos casualizados com seis repetições. Cada parcela constou de cinco plantas/frasco. Os dados foram submetidos à análise de variância e de regressão. Concluiu-se que o crescimento da parte aérea e da raiz foi progressivo ao longo do período de enraizamento. O surgimento dos primórdios da raiz ocorreu a partir dos oito dias de permanência no meio de enraizamento in vitro.
\end{abstract}

Palavras-chave: Gypsophila paniculata, micropropagação, ápices caulinares, crescimento.

\begin{abstract}
Growth evaluation of Gypsophila paniculata during in vitro rooting

Gypsophila paniculata is a cutting flower that belongs to the Caryophyllaceae family. Known popularly as 'mosquitinho' it is marketed for making arrangements and bouquets. The sexual propagation results in disuniform plants because of the genetic segregation. On the other hand, the vegetative propagation allows dissemination of plant pathogens when infected plants are used. Through the micropropagation technique it is possible to obtain the heterose fixation and pathogen free young plants on a commercial scale. In vitro rooting was analyzed in Gypsophila paniculata plants at different periods of cultivation. Fresh and dry aerial and rooting matter were evaluated at $4 ; 8 ; 12 ; 16 ; 20$ and 24 days. The experimental units were arranged according to a randomized block design with six replicates, each replicate being a pot with five plants. The data were submitted to variance and regression analysis. The results allowed to conclude that both shoot and root growth were progressive along the rooting days. Root primordial appeared after eight days in the rooting media.
\end{abstract}

Keywords: Gypsophila paniculata, micropropagation, caulinar apexes, growth.

\section{(Recebido para publicação em 15 de maio de 2002 e aceito em 19 de maio de 2003)}

$G^{3}$ ypsophila paniculata é uma angiosperma que pertence à família Caryophyllaceae. Conhecida popularmente como "mosquitinho", suas inflorescências são formadas por flores pequenas e brancas as quais são comercializadas para serem utilizadas na confecção de arranjos e buquês (Lorenzi \& Souza, 1995).

Dados de produção e comercialização citam a Gypsophila paniculata como uma das principais flores de corte, sendo apontada como o terceiro produto mais comercializado na CEAGESP e um dos dez mais vendidos no Veiling da Holambra-SP (Castro, 1998).

A reprodução sexuada desta espécie é antieconômica pelo alto custo das sementes e indesejável porque gera plantas geneticamente segregantes, reduzin- do a qualidade e o valor comercial (Castro,1993). A propagação pelo método vegetativo é lenta e inviabiliza grandes produções. Nesse sentido, Grattapaglia \& Machado (1998), citam que a micropropagação, traz como vantagens a manutenção da heterose, a multiplicação rápida em períodos de tempo e espaço físico reduzidos e a geração de mudas livres de patógenos em escala comercial.

A multiplicação é uma etapa da micropropagação na qual o objetivo principal visa obter um maior número de hastes através de sucessivos subcultivos (Debergh \& Read, 1990). Castro et al. (1996), pesquisando propagação de Gypsophila paniculata em três diferentes meios de cultivo, não obtiveram diferença significativa para proliferação de brotos. Após 60 dias de cultivo, obtiveram 4,2; 4,7 e 4,8 brotos por explante, nos meios analisados. Também Zuker et al. (1997) realizaram estudos visando testar a capacidade de regeneração de brotos adventícios para seis cultivares de Gypsophila paniculata. A resposta foi positiva, com regeneração eficiente para todas as cultivares.

A fase de enraizamento caracterizase pela formação de raízes adventícias nas partes aéreas do caule provenientes da multiplicação. A rizogênese ocorre de uma a três semanas e segundo Hartmann \& Kester (1990), divide-se em iniciação e elongação das raízes. Experimentos com enraizamento in vitro foram realizados por Teo \& Chan (1994), com microestacas de Carica

\footnotetext{
${ }^{1}$ Parte integrante da dissertação de mestrado do primeiro autor, realizada na FAMV/UPF.
} 
papaya L., após três a quatro dias de tratamento com AIB, a extremidade basal da microestaca apresentou aparência de calo e deste tecido surgiram indicações de raiz. Entretanto, o processo de enraizamento foi verificado entre sete e oito dias.

Silva et al. (1995) estudaram o efeito da idade das raízes emergidas in vitro, substratos e espécies (pau-santo, mandioca, batata-doce e amora preta) na capacidade de aclimatização ex vitro. Os resultados demonstraram que o maior índice de sobrevivência está ligado à espécie, não sofrendo influência de nenhum substrato e nem da idade da raíz.

A obtenção de uma planta com um sistema radicular bem desenvolvido é de grande importância para sua sobrevivência e crescimento nas novas condições ambientais. O tipo do sistema de raízes, obtido no enraizamento in vitro, também determina o sucesso do transplante, sendo as raízes mais curtas as mais adequadas, uma vez que apresentam-se na fase de crescimento ativo, facilitando a pega da planta (Grattaplagia \& Machado, 1990). Para Debergh (1991), o processo de enraizamento é muito complexo incluindo fatores fisiológicos, bioquímicos e biológicos que interagem com os fatores ambientais. Além disso, a complexidade é aumentada pela multiplicidade de espécies e cultivares acompanhadas pela variabilidade biológica.

Segundo Benincasa (1988), a partir dos dados de crescimento pode-se estimar, as causas de crescimento entre plantas geneticamente diferentes ou entre plantas crescendo em ambientes diferentes. O crescimento de uma planta pode ser estudado através de medidas de diferentes tipos: lineares (altura, comprimento entre outros), superfície (área foliar), peso e unidades estruturais. $\mathrm{O}$ presente trabalho teve como objetivo analisar o crescimento de plantas de Gypsophila paniculata durante o enraizamento in vitro em diferentes épocas de cultivo.

\section{MATERIAL E MÉTODOS}

O trabalho foi desenvolvido no laboratório FAMV/UPF, de agosto de 2000 a janeiro de 2001. O experimento foi conduzido com plantas de Gypsophila paniculata, cultivar Bristol Fairy, oriundas do viveiro da FAMV/UPF.

Das hastes coletadas foram retiradas as folhas. As hastes foram lavadas com água e desinfestadas com álcool 70\%, por cinco segundos. Posteriormente, foram transferidas para uma solução de $1,5 \%$ de hipoclorito de sódio, acrescido de três gotas de tween-20 (1 gota para cada $100 \mathrm{ml}$ ), durante dez minutos, e em seguida, foram feitas quatro lavagens com água destilada e esterilizada. Os ápices caulinares $(1 \mathrm{~mm})$ foram excisados em capela de fluxo laminar com auxílio de lupa estereomicroscópica, bisturi, pinças e placas de Petri, previamente esterilizados. Os ápices foram transferidos para tubos de ensaio $(25 \times 150 \mathrm{~mm})$ contendo meio de isolamento estéril $(15 \mathrm{ml})$, composto por macro e micronutrientes e vitaminas do meio básico $\mathrm{MS}$ (Murashige \& Skoog, 1962), suplementado com $1,0 \mathrm{mg} \cdot \mathrm{L}^{-1} \mathrm{de}$ benzinoaminopurina (BAP), 0,01 mg. $\mathrm{L}^{-1}$ de ácido naftalenoacético (ANA) e 0,1 mg. $L^{-1}$ de ácido giberélico $\left(\mathrm{GA}_{3}\right), 6$ g.L $\mathrm{L}^{-1}$ de ágar e 30 g. $\mathrm{L}^{-1}$ de sacarose. $\mathrm{O} \mathrm{pH}$ do meio de cultura foi ajustado em 5,9 com $\mathrm{NaOH}$. Foi esterilizado em autoclave (1 atm) a $120^{\circ} \mathrm{C}$, por vinte minutos. Posteriormente, os explantes em tubos de ensaio foram transferidos para um ambiente escuro por três dias em sala de cultura. Transcorrido esse período, foram colocados em uma sala de crescimento com luz (lâmpadas fluorescentes e temperatura controladas $(12 \mathrm{~h} \mathrm{luz} /$ dia a $25^{\circ} \mathrm{C} \pm 2^{\circ} \mathrm{C}$ e luminância de $\pm 25 \mathrm{mmol}$. $\left.\mathrm{m}^{-2} \cdot \mathrm{s}^{-1}\right)$. Os explantes permaneceram nestas condições por um período de 60 dias, quando foi feito o primeiro subcultivo.

Os propágulos $(2 \mathrm{~cm})$ obtidos por subcultivos, foram transferidos para frascos com capacidade de $300 \mathrm{ml}$, contendo aproximadamente $50 \mathrm{ml}$ de meio MS, suplementado com 0,4 mg.L $\mathrm{L}^{-1}$ de Tiamina-HCl, $100 \mathrm{mg} . \mathrm{L}^{-1}$ de mioinositol, 0,05 mg. $\mathrm{L}^{-1}$ de ANA, 1,0 mg. $\mathrm{L}^{-1}$ de BAP, 40 g.L . $^{-1}$ de sacarose e 7 g.L L $^{-1}$ de ágar, o qual se constituiu no meio de multiplicação.

As mudas multiplicadas na etapa anterior foram repicadas para meio de enraizamento MS acrescido de 0,5 mg. $\mathrm{L}^{-1}$ de ácido indolbutírico (AIB), 30 g. $\mathrm{L}^{-1}$ de sacarose e 6 g. $\mathrm{L}^{-1}$ de ágar, onde permaneceram por $4 ; 8 ; 12 ; 16 ; 20$ e 24 dias, os quais se constituíram nos tratamentos. O delineamento experimental utilizado foi de blocos casualizados com seis repetições. Cada parcela constou de um frasco com cinco explantes. Em cada data de avaliação, foram analisadas matéria fresca e seca da raiz (MFR e MSR) e parte aérea (MFA e MSA).

A massa da matéria seca foi obtida via secagem em estufa a $65^{\circ} \mathrm{C}$ até peso constante. A matéria fresca e seca da parte aérea e das raízes das plantas de Gypsophila paniculata foi determinada em uma balança digital analítica. Os resultados foram submetidos à análise de variância e de regressão.

\section{RESULTADOS E DISCUSSÃO}

Observou-se resposta positiva para todas as variáveis estudadas no que se refere às diferentes datas em que as mudas de Gypsophila paniculata foram colocadas para enraizar in vitro.

$\mathrm{O}$ crescimento da matéria fresca e seca da parte aérea apresentou um comportamento linear (Figura 1), indicando aumento no crescimento da muda ao longo do período testado. Calcula-se o aumento de 21,68 mg de matéria fresca da parte aérea para cada dia que as mudas permaneceram no meio de enraizamento in vitro $\left(\mathrm{R}^{2}=0,95\right)$. Entretanto, para a formação da matéria seca da parte aérea, foi imprimido um crescimento de 2,45 mg, com um $\mathrm{R}^{2}$ equivalente a 0,98 .

Resultados semelhantes foram encontrados por Silva et al. (1995) ao trabalharem com plantas de Ipomea batatas e Manihot esculenta. Estes autores obtiveram resposta linear positiva no crescimento de matéria da folha no período de enraizamento in vitro.

Com relação à matéria fresca e seca das raízes de brotações de Gypsophila paniculata, nas diferentes datas em que foram enraizadas, verificou-se também um comportamento linear (Figura 2). Estima-se um aumento de 6,34 mg de matéria fresca de raiz a cada dia em que as mudas permaneceram no meio de enraizamento in vitro, apresentando um coeficiente de correlação de 0,87 . Por outro lado, cada dia no meio de enraizamento promoveu acréscimo de 




Figura 1. Matéria fresca e seca da parte aérea no período de enraizamento in vitro. Passo Fundo, FAMV/UPF, 2001.

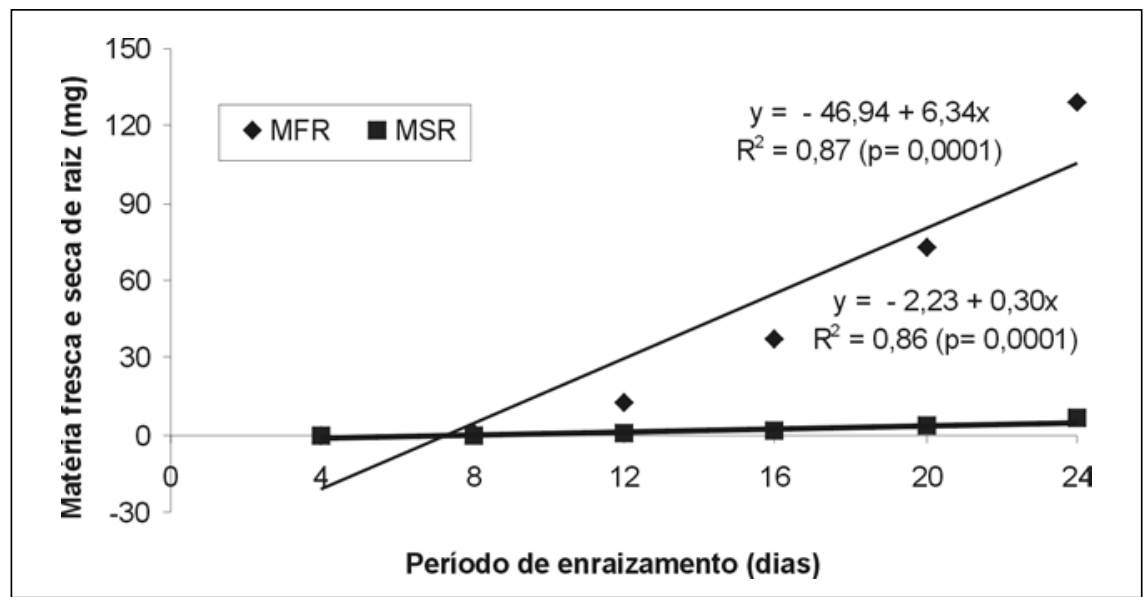

Figura 2. Matéria fresca e seca de raiz no enraizamento in vitro. Passo Fundo, FAMV/UPF, 2001.

$0,30 \mathrm{mg}$ na matéria seca por crescimento diário com $\mathrm{R}^{2}=0,86$.

Observou-se que o surgimento das raízes adventícias ocorreu, aproximadamente, oito dias após os propágulos terem sido transferidos para o meio de enraizamento. Nessa data, os valores de matéria fresca e seca da raiz foram de 0,33 e $0,003 \mathrm{mg}$, respectivamente. Aos doze dias, verificou-se que a MFR passou a $12,14 \mathrm{mg}$ e a MSR a $0,64 \mathrm{mg}$. Hartmann \& Kester (1990) descrevem o surgimento das raízes ocorrendo em dois períodos básicos: o primeiro caracteriza-se pelo período de iniciação com duração de 4-8 dias, que se subdivide em formação do meristema com intensa atividade de auxina e início da formação das raízes sem necessidade deste regulador; um segundo período caracteriza-se pela elongação radicular, no qual os tecidos que darão origem ao primórdio se desenvolvem, rompem os tecidos internos e emergem na epiderme.

Teo \& Chan (1994) observaram início no enraizamento de Carica papaya L. após três a quatro dias de permanência no meio de cultivo; a extremidade basal da microestaca apresentou aparência de calo e deste tecido surgiram primórdios de raiz. Entretanto, registraram-se as primeiras ocorrências entre sete e oito dias. Resultados semelhantes foram verificados por Castro \& Andrade (1995), ao detectarem em batata doce o surgimento de raízes in vitro, em torno do sétimo dia de cultivo. Da mesma forma, Hilare et al. (1996), ao estudarem anatomicamente o desenvolvimento de raízes adventícias in vitro com Mussaenda erythrophylla L., observaram atividade meristemática no quarto dia e o surgimento de raízes primordiais no sexto dia. No presente tra- balho foi observado o aparecimento de primórdios da raiz aos oito dias de permanência no meio de enraizamento.

Em relação ao crescimento das raízes, resultados semelhantes foram encontrados por Pereira et al. (1999), os quais obtiveram crescimento linear em relação ao número de raízes formadas ao longo de 32 dias de cultivo in vitro para duas cultivares de morangueiro Hofla e Tangi. Também Hoffmann et al. (2001) obtiveram para a variável porcentagem de enraizamento um crescimento linear ao longo do tempo, ao estudarem o enraizamento in vitro de dois porta-enxertos de macieira (Marubakaido e M-26), em sete diferentes períodos (7-49 dias). Portanto, o crescimento da parte aérea e da raiz das mudas de Gypsophila paniculata cultivar Bristol Fairy foi progressivo ao longo dos dias de enraizamento, com surgimento dos primórdios da raiz a partir dos oito dias de permanência no meio de cultivo in vitro.

\section{AGRADECIMENTOS}

Os autores agradecem à Coordenação de aperfeiçoamento de Pessoal de Nível Superior (CAPES) pela concessão de bolsa de mestrado e à Fundação de Amparo a Pesquisa do Rio Grande do Sul (FAPERGS) pela bolsa de Iniciação Científica.

\section{LITERATURA CITADA}

BENINCASA, M.M.P. Análise de crescimento de plantas (noções básicas). Jaboticabal: FUNEP, 1988. 42 p.

CASTRO, C.E.F.; SILVEIRA,R.B.A.; PEREIRA, I.T.D.M. Propagação de Plantas Ornamentais: Cultura de Tecidos. In: CASTRO, C.E.F. (Ed.).Manual de Floricultura, Maringá: UEM,1993. p. 74-79.

CASTRO, O.F.A.; ANDRADE, A.G. Cultura in vitro de batata-doce (Ipomea batatas (L.) LAM.). Pesquisa Agropecuária Brasileira, Brasília, v. 30, n. 7, p. 917-922, 1995.

CASTRO, M.V.; DARDEL, C.H.; VERDUGO, G.R. Propagación in vitro de Gypsophila paniculata L. Agricultura Técnica, v. 56, n. 3, p. 224-228, 1996.

CASTRO, C.E. Os atores da cadeia produtiva de flores e plantas ornamentais. Revista Brasileira de Horticultura Ornamental, Campinas, v. 4, n.1/ 2, p. 1-46, 1998.

DEBERGH, P.C. Aclimatization Techniques of Plants from in vitro. Acta Horticulturae, n. 289, p. 291-300, 1991. 
DEBERGH, P.C.; READ, P.E. Micropropagation. In: DEBERGH, P.C; ZIMMERMANN, P.C. (ED.s) Micropropagation - Technology and application. Kluver: Academic Puyblishers, 1990. p. 1-13.

GRATTAPAGLIA, D.; MACHADO, M.A Micropropagação. In: TORRES, A.C.; CALDAS L.S.; BUSO, J.A.(Ed.). Cultura de tecidos e transformação genética de plantas. Brasília: EmbrapaSPI/Embrapa-CNPH, 1998. p.183-260.

HARTMANN, H.T.; KESTER, D.E. Propagación de plantas-Principios y praticas. México: Continental, 1990. 760 p.

HILARE, R.; BERWART, C.A.; MUNÕZ, C.A. Adventitious root formation and development in cuttings of Mussaenda erythrophylla L. HortScience, v. 31, n. 6, p. 1023-1025, 1996.
HOFFMANN, A.; CHALFUN, N.N.J.; VIEIRA, S.S.N. Substratos na indução e desenvolvimento in vitro de raízes em dois porta-enxertos de macieira. Pesquisa Agropecuária Brasileira, Brasília, v. 36, n. 11, p. 1371-1379, 2001.

LORENZI, H.; SOUZA, H.M. Plantas ornamentais do Brasil - Arbustivas, herbáceas e trepadeiras. São Paulo: Plantarum, 1995, 720 p.

MURASHIGE, T.; SKOOG, F. A revised medium for rapid growth and bioassay with tobacco tissue cultures. Physiologia Plantarum, v. 15, p. 473-497, 1962.

PEREIRA, J.E.S.; BIANCHI, V.J.; DUTRA, L.F.; FORTES, R.F. Enraizamento in vitro de morangueiro (Fragaria $\mathrm{x}$ ananassa Duchesne) em diferentes concentrações do meio MS. Ciência Rural, Santa Maria, v. 29, n. 1, p. 17-20, 1999.
SILVA, A.T.; PASQUAL, M.; ISHIDA, J.S; ANTUNES, L.E.C. Aclimatação de plantas provenientes da cultura in vitro. Pesquisa Agropecuária Brasileira, Brasília, v. 30, n. 1, p. 49-53, 1995.

TEO, C.K.H.; CHAN, L.K. The effects of agar content, nutrient concentration, genotype and light intensity on the in vitro rooting of papaya microcuttings. Journal of Horticultural Science, v. 69, n. 2, p. 267-273, 1994.

ZUKER, A.; AHRONI, A.; SHEJTMAN, H; VAINSTEIN, A. Adventitious shoot regeneration from leaf explants of Gypsophila paniculata $\mathrm{L}$. Plant Cell Reports, v. 16, p. 775-778, 1997. 